\title{
Mechanical strength of ground WC-Co cemented carbides after coating deposition
}

\author{
J.Yang ${ }^{\mathrm{a}, \mathrm{b}^{* 1}}$, M.Odén $^{\mathrm{b}}$, M.P. Johansson-Jõesaar ${ }^{\mathrm{b}, \mathrm{c}}$, J. Esteve ${ }^{\mathrm{d}}$ and L.Llanes ${ }^{\mathrm{a}, \mathrm{e}}$ \\ ${ }^{a}$ CIEFMA - Departament de Ciència dels Materials i Engenyeria Metal-lúrgica, Campus Diagonal Besòs-EEBE, \\ Universitat Politècnica de Catalunya, Barcelona 08019, Spain \\ ${ }^{b}$ Nanostructured Materials, Department of Physics, Chemistry, and Biology (IFM), Linköping University, Linköping \\ 58183, Sweden \\ ${ }^{\mathrm{c}} \mathrm{SECO}$ Tools AB, Fagersta 73782, Sweden \\ ${ }^{\mathrm{d}}$ Departament de Física Aplicada i Òptica, Universitat de Barcelona, Barcelona 08028, Spain \\ ${ }^{\mathrm{e}} \mathrm{CRnE}$ - Center for Research on Nanoengineering, Campus Diagonal Besòs-EEBE, Universitat Politècnica de \\ Catalunya, Barcelona 08019, Spain \\ jing.yang1@upc.edu \\ jinya@ifm.liu.se \\ jing.yang@ames-sintering.com \\ "Corresponding author:
}

\begin{abstract}
Manufacturing of hardmetal tools often involves surface grinding, ion etching and final coating. Each stage throughout the manufacturing chain introduces surface integrity changes which may be critical for defining the final mechanical behavior of the coated tools. Within this context, an experimental test program has been developed to assess the influence of a coating (TiN) deposition on surface integrity and transverse rupture strength of a previously ground finegrained WC-Co grade substrate. Four different substrate surface finish conditions (prior to ion etching and coating) were evaluated: as sintered (AS), ground $(\mathrm{G})$, polished $(\mathrm{P})$, and ground plus high temperature annealing (GTT). Surface integrity and fracture resistance characterization, complemented with a detailed fractographic analysis, were performed on both uncoated and coated samples. Results show that the surface integrity after grinding has been partly modified during the ion etching and film deposition processes, particularly in terms of a reduced compressive residual stress state at the substrate surface level. Consequently, the grinding induced strength enhancement in hardmetals is reduced for coated specimens. Main reason behind it is the change of nature, location and stress state acting on critical flaw: from processing defects existing at the subsurface (uncoated $G$ specimens) to grinding-induced microcracks located close to the interface between coating and substrate, but within the subsurface of the
\end{abstract}

\footnotetext{
${ }^{1}$ Current address: AMES-Sintered Metal Components, Camí de Can Ubach, 8, Pol. Ind. "Les Fallulles”, 08620 Sant Vicenç dels Horts, Barcelona - Spain
} 
latter (coated G specimens). This is not the case for AS and P conditions, where flexural strength does not change as a result of ion etching and coating. Finally, fracture resistance increases slightly for GTT specimens after coating process, possibly caused by a beneficial effect of the deposited film on the residual stress state at the surface.

Keywords: Cemented carbides; Grinding; Coating; Ion etching; Surface integrity; Transverse rupture strength

\section{Introduction}

WC-Co cemented carbides, often simply termed as hardmetals, represent the backbone of the tool manufacturing industry [1]. They exhibit exceptional combinations of hardness, toughness, strength and wear resistance, which are the result of the different properties of their two interpenetrating constituents: hard and brittle tungsten carbide, and soft and ductile cobalt-base binder [2-5].

Fracture strength is a relevant mechanical parameter for quality control and validation of material production and design. At room temperature, hardmetals exhibit brittle fracture behavior at the macroscopic level, due to the large volume fraction of the carbide phase. However, at the microscopic one, ductile fracture features are evidenced within the metallic binder phase. In general, failure of hardmetals takes place through catastrophic propagation of either preexisting (processing) or service-induced defects [6]. It is well established that strength of hardmetals is determined by microstructural parameters, which define fracture toughness as an intrinsic property, as well as critical flaws (eg. pores, inclusions, large carbides, phase clusters, etc. [3, 69]). The latter one includes consideration of the effective stress state acting on the failurecontrolling defects, which depends on the effective size, shape and distribution of the existing flaws. 
Hardmetal tools are produced through a powder metallurgy, liquid-phase sintering route. In the case of cutting tools, the final product usually includes machining to the desired geometry and coating deposition to achieve improved wear resistance during service [10-12]. Diamond wheel grinding has been the industrial primary choice for machining the hardmetals. It involves an intensive abrasive action that introduces alterations at the surface and subsurface levels: damage, residual stresses as well as microstructural and metallurgy changes [13-15]. On the other hand, surface integrity inherited from grinding may be further modified during ion etching (surface cleaning step prior to deposition) or film deposition. In both cases the surface is subjected to bombardment of energetic ions, which may affect both the hardmetal substrate and the deposited coating $[16,17]$. Investigating and understanding the specific surface integrity changes ascribed to each manufacturing stage; and in turn, their effect on mechanical and tribological properties, are critical for defining the final performance and relative manufacturing cost of cutting tools $[10,11,18-21]$.

Within this context, in addition to the referred factors (eg. microstructure and processing flaws) affecting strength of hardmetals, this mechanical parameter is particularly sensitive to surface integrity resulting from machining, either abrasive (grinding) or non-abrasive (eg. electrical discharge machining) and coating stages, especially in term of induced subsurface damage and residual stresses. Accordingly, strength is effectively defined by the combined influence of the depth and magnitude of the residual stresses induced within the subsurface, geometry of the induced cracks, and the synergic interaction of these features with microstructure and processing defects [22-27]. Studies reporting the combined influence of grinding and coating on induced changes in residual stress state, adhesion strength, and contact damage resistance exist [20, 2831]. However, information of how grinding and coating collectively affect the fracture resistance is limited for these materials $[32,33]$. In this paper we report a systematic approach to assess the influence of grinding and subsequent coating on the transverse rupture strength of a WC-Co cemented carbide grade. Four different surface finish conditions were characterized with respect to surface integrity and fracture resistance. The rupture tests were evaluated by fractographic analysis on both uncoated and coated samples. 


\section{Experimental procedure}

The WC-Co hardmetal studied in this work comprises 13 wt.\% metallic binder content and a mean carbide grain size of $0.7 \mu \mathrm{m}$. The Vickers hardness (HV30) and fracture toughness $\left(\mathrm{K}_{\mathrm{Ic}}\right)$ of this material are 14.8 $\mathrm{GPa}$ and 11.2 $\mathrm{MPa} \sqrt{\mathrm{m}}$, respectively [34]. Test specimens were manufactured as bars with the dimensions $4 \times 4 \times 53 \mathrm{~mm}^{3}$. Prior to coating deposition, four substrate surface finish conditions (applied on the $4 \times 53$ longitudinal side) were prepared: as sintered (AS), ground (G), polished (P) and ground plus thermal treatment (GTT). The G condition was obtained by means of conventional abrasive diamond wheel grinding of AS samples, and using a liquid coolant to prevent heat generation. The $\mathrm{P}$ surface finish results from further and sequential material removal stages, using diamond-containing discs, diamond suspensions down to $3 \mu \mathrm{m}$, and a final step with a $45 \mathrm{~nm}$ silica colloidal suspension. The GTT condition was attained by annealing several $\mathrm{G}$ specimens in vacuum at $920^{\circ} \mathrm{C}$ for $1 \mathrm{~h}[2,22,35$, 36].

Prior to physical vapor deposition (PVD) of the ceramic film, all the specimens were ultrasonically cleaned in an alkali bath and alcohol. Then, they were sputter cleaned using Ar-ion etching in a high vacuum chamber $\left(2.0 \times 10^{-3} \mathrm{~Pa}\right)$, with a bias $\sim 500 \mathrm{eV}$ during $30 \mathrm{~min}$. This wetchemical / ion bombardment cleaning is a standard practice within PVD route to remove contamination and reaction layers as well as to activate the substrate surface. In order to assess changes induced on residual stresses at the surface due to this ion-etching (I-E) stage, some G and $\mathrm{P}$ specimens were not coated. They are then referred to as $\mathrm{G}+\mathrm{I}-\mathrm{E}$ and $\mathrm{P}+\mathrm{I}-\mathrm{E}$ respectively.

TiN coating was finally deposited on most of the specimens studied, independent of surface finish condition, using an industrial scale MZR323 reactive cathodic arc evaporation system. The arc deposition was conducted from pure Ti-cathodes in a $\mathrm{N}_{2}$ atmosphere (2 Pa) using a substrate bias of $-50 \mathrm{~V}$, and a substrate temperature of $450{ }^{\circ} \mathrm{C}$.

The surface integrity was evaluated in terms of subsurface damage, and residual stress. Examination of subsurface features was conducted on cross-sections milled with a focused ion beam (FIB) Zeiss Neon 40 system. Residual stresses were determined by X-ray diffraction (XRD) 
with a Panalytical Empyrean four- circle diffractometer using a $\mathrm{Cu}-\mathrm{K}_{\alpha}$ radiation, performed in $\psi$ geometry and point focus mode. For the substrate surface, stresses were only determined in the WC phase due to a relative low amount of the binder phase, mainly cobalt, resulting in too weak and broad diffraction peaks and hence inconclusive stress measurements. The WC 211-peak position $\left(2 \theta \sim 117^{\circ}\right)$ and the TiN coating 220 -peak position $\left(2 \theta \sim 62^{\circ}\right)$ were recorded for 4-8 $\psi$ angles between 0 and $57^{\circ}$ by fitting a Gauss or Pseudo-Voigt function to the diffraction data. The stresses were then calculated by applying the $\sin ^{2} \psi$-d method using X-ray elastic constants for WC 211-peak ( $\mathrm{E}=491 \mathrm{GPa}$ and $v=0.2)$ and TiN 220-peak ( $\mathrm{E}=424 \mathrm{GPa}$ and $v=0.2$ ) from Eigenmann and Macherauch [37]. Under these conditions, in the case of WC phase, the X-ray penetration depth was approximately $1.1 \mu \mathrm{m}$ with $50 \%$ of the diffracted intensity scattered from a layer extending to the penetration depth. Accordingly, aiming to evaluate the grinding-induced residual stress profile, measurements were performed at different depths (in 2-micron steps approximately down to about $12 \mu \mathrm{m}$ ) below the surface. The different depths were achieved by systematic layer removal by mechanical polishing using $1 \mu \mathrm{m}$ diamond suspension. Although the biaxial residual stresses were only measured in the WC phase, the results represent a good approximation for the surface grinding-induced deviatoric macrostress [13, 38]. Based on previous reports [39-42], microstress values in the range from -100 to $-500 \mathrm{MPa}$ are to be expected in the WC phase, which are caused by the differences in elastic properties and coefficient of thermal expansion between WC and the binder. The expected small changes in microstress caused by machining and coating are implicitly captured in the biaxial stress state measurements.

Mechanical tests were conducted to evaluate the correlation between surface integrity and flexural strength of all the specimens studied. The strength was measured with a fully articulating jig fixture in a four-point bending configuration, with inner and outer spans of 20 and $40 \mathrm{~mm}$, respectively. The longitudinal section with the surface finish of interest was the one subjected to the maximum tensile stress. Flexure tests were conducted using a universal testing machine (Model 8511, Instron, Ltd.) in a room-air environment. Before testing, the longitudinal edges of all the samples were chamfered. A variable number of specimens, between five and thirteen, were tested for each surface condition. Finally, extensive and discriminative fractography was conducted by optical method and FESEM (field-emission scanning electron 
microscope). For each specimen, possible fracture initiation sites were first traced back, at low magnification, from sequential sets of fracture surface markings. Particular areas of interest were then examined at higher magnification in order to characterize, when it was possible, strengthlimiting flaws. 


\section{Results and discussion}

3.1 Surface integrity changes associated with sequential grinding, ion-etching and film deposition

Aiming at comprehensive interpretation of grinding and subsequent coating effects on the mechanical strength of the studied cemented carbides, surface integrity alterations resulted from these manufacturing stages are necessary to be addressed. Grinding involves both mechanical and thermal loads; the later ones being often suppressed by using a coolant. The corresponding changes may include plastic deformation, microcracking, phase transformations and residual stresses generation at both surface and subsurface levels [13-15]. Additional changes are induced during the subsequent ion etching and coating deposition process steps, yielding a new surface condition $[11,20]$.

The influence of these different manufacturing stages on subsurface integrity and residual stress state has previously been reported for the hardmetal grade studied [29, 30]. The main findings related to grinding may be summarized here. Figure 1 illustrates grinding-induced damage and residual stresses using the same depth scale. On one hand, microcracked carbides embedded in a heavily deformed metal binder are found within a subsurface layer of about 1 micron in depth. On the other hand, compressive residual stresses are discerned from the surface into depths wellbeyond the thickness estimated for the deformed/damaged layer. Such residual stresses are not homogeneously distributed, as they gradually decrease from -1.8 GPa at the surface to baseline values at depths about 10-12 microns. Finally, surface integrity of GTT specimens corresponded to a damage scenario inherited from $G$ samples, but free of surface and subsurface residual stresses.

Concerning the subsequent ion etching and coating process steps, Figure 2 presents FIB-milled cross-section view of a ground, ion-etched and finally coated hardmetal. Although ion etching removes material from the surface, grinding induced damage in terms of microcracks was still apparent after coating deposition. 
Significant changes of the surface residual stress levels at the WC-Co substrate were observed and associated with ion etching and coating processes. Values measured in the WC phase, at the surface level of substrate, for each surface condition and coating process step: uncoated; ionetched $(+\mathrm{I}-\mathrm{E})$ and coated $(+\mathrm{C})$, are given in Figure 3. As observed, during ion etching, the grinding-induced stress is reduced with about $50 \%$ (down to $-0.9 \mathrm{GPa}$ ), as a combined effect of material removal and thermal treatment during etching. Residual stress values further decrease after the coating process due to the combined effect from extended thermal exposure and stresses caused by the difference in coefficient of thermal expansion between substrate and coating. Internal balance of the residual stress state at the interface level, where the high intrinsic compressive residual stresses assessed for the TiN film (about -3.3 GPa, independent of surface finish) should be considered, may also contribute in resulting coated samples exhibiting a residual stress level slightly lower than the ones prior to coating $[19,20]$. On the other hand, baselines values (lower than -0.3 GPa) measured for all the AS and P specimens (uncoated, ionetched and coated) point out that residual stresses at the substrate surface for these two variants can be neglected. This is also the case for all GTT-related specimens, as referred above.

\subsection{Coating deposition effects on fracture behavior of ground hardmetals}

Mean and standard deviation values for the transverse rupture strength $\left(\sigma_{f}\right)$ of all the surface variants investigated are shown in Figure 4. AS and $\mathrm{P}$ samples are considered to display the intrinsic flexural strength of the hardmetal here studied, since neither surface damage nor additional surface residual stresses exist for these conditions. The $G$ specimens exhibit a noticeable enhancement of the flexural strength compared to that of the AS and P samples. This behavior is in good agreement with previous studies on uncoated ground specimens [23, 25]. In the referred studies, the strength enhancement was directly related to the high compressive surface residual stresses. However, the as-measured strength enhancement in that study is less than what was expected from estimations made by assuming a superposition of residual and externally applied stresses acting on the existing surface defects introduced by grinding. 
After the ion etching and coating processes, the ground and coated specimens show lower transverse rupture strength values than the uncoated ones. The decay in strength is expected since the grinding-induced surface residual stresses is reduced during sputter cleaning and film deposition (Figure 3). However, the reduction of residual stress does not match with the difference in flexural strength for the corresponding uncoated and coated samples. The strength for the AS and $\mathrm{P}$ samples does not change after ion etching and coating deposition. In addition, a significant increase of strength was detected for the etched and coated GTT samples, even though the residual stress of hardmetal surface for the GTT surface condition was unaffected by etching and coating deposition. Nevertheless, the strength for coated GTT samples was still found to be lower than that of the coated G samples. These facts emphasize the beneficial role of the originally grinding-induced residual stresses, remnant after ion etching and coating (about $0.9 \mathrm{GPa})$.

A systematic fractographic examination of all the broken pieces from the rupture tests was conducted in order to improve the understanding of surface integrity by identifying the nature and location of the transverse rupture strength controlling flaws for the different surface condition used in this study. Overall, with the objective to understand the ion-etching and coating effects on flexure strength, a baseline of the behavior for the uncoated specimens needs to be established. Fractography results for uncoated G, P and GTT samples have previously been reported [27]. Representative failure scenarios are given in Figure 5, and can be summarized as follows: (1) for $\mathrm{G}$ and $\mathrm{P}$ specimens, failure initiation is always associated with intrinsic processing flaws (pores, inclusions or large carbides); (2) for G samples, critical flaws are always subsurface located (at depths between 10 and $300 \mu \mathrm{m}$ ); (3) for $\mathrm{P}$ specimens, the location of critical defects is undefined since they are found either at or below the surface for different specimens; and (4) for GTT specimens, failure initiation site is clearly located at the surface, while discrete critical flaws cannot be determined since they are embedded within larger areas of grinding-induced damage. The failure scenario for the AS specimens is similar to that for the $\mathrm{P}$ samples. By combining the residual stress and flexural strength measurements with the above failure scenarios indicate that the improved strength for the $\mathrm{G}$ specimens mainly results from an effective shift in location of the failure controlling flaws from the surface to subsurface levels. This is further validated by the fact that, once the residual stresses are relieved by a subsequent 
annealing (GTT), the location of the flaw initiating failure is shifted back to the surface and correlated to grinding-induced damage, i.e., the fracture is initiated where maximum tensile stress is applied during the bending test.

Figure 6 shows the nature and location of critical flaws, for coated specimens with the different surface finish condition. Several observations may be highlighted. First, different from the typical scenario found for uncoated $G$ samples, only a few coated specimens display critical flaws located at the subsurface level, and instead locations at the surface dominates, i.e. at the interface between the substrate and coating. It means that the failure scenario of the coated $\mathrm{G}$ specimens is similar to the one seen for uncoated GTT specimens (Figure 6a). Hence, the lower strength observed for coated G specimens should be related to two reasons: change in nature and location (now at the surface) of the critical flaws, and effective stress state at the surface resulting from superposition of applied external (maximum there), grinding-induced (reduced after ion etching and film deposition stages) and coating's intrinsic stresses. This is not the case for AS and P samples, where intrinsic processing defects (pores or inclusions), located at either the surface or subsurface are still the flaws controlling strength (Figure 6b). As a consequence, the effects of applying a coating on the transverse rupture strength of AS and P samples are negligible. Finally, coating deposition does not seem to affect the nature and location of the critical flaws for GTT specimens, i.e. they remain linked to grinding-induced surface damage (Figure 6c). However, a slight strength increase for coated GTT samples was measured. Considering that both uncoated and coated GTT samples did not exhibit any difference in surface residual stress, the observed strength increase should be rather ascribed to factors intimately associated with the presence of the TiN-coating, i.e. a dense film with high compressive stresses within the coating layer, the extremely good adhesion existing on the studied coating-substrate systems [29], and a geometry-related less severe nature of the effective critical flaw [32]. 


\section{Summary}

A systematic experimental test program was conducted to assess the influence of grinding surface pretreatment and the subsequent application of an arc-deposited TiN coating on the flexural strength of a fine-grained WC-Co substrate. Four different surface pretreatment conditions were considered, i.e., as sintered (AS), ground $(\mathrm{G})$, polished $(\mathrm{P})$, and ground plus high temperature annealing (GTT). It was found that ion etching and coating stages clearly affect surface integrity previously induced by grinding. In this regard, removal of material from the surface during ion etching, extended thermal treatment, and the presence of a coating resulted in a significant residual stresses decrease (about half of its original value). However, damage induced by grinding was not completely removed, and some microcracks were still left on the substrate surface (close to the interface). On the other hand, high temperature annealing (GTT) yielded a complete relief of the grinding-induced residual stresses, but without inducing any additional change in terms of existing microcracks and depth of the damaged layer.

The transverse rupture strength enhancement observed for ground WC-Co, as compared to AS and $\mathrm{P}$ conditions, was partly lost for the corresponding coated specimens. The influence of ion etching and coating deposition on strength was correlated to the reduction of residual stress level triggering a shift in the location of the critical flaw from the subsurface to the surface region. In this regard, it should be noticed that measured strength values include the effect of intrinsic stresses within the layer, because the surface-like nature of the critical flaw. This was not the case for AS and P specimens, where strength was always controlled by intrinsic defects for both uncoated and coated specimens indicating that the effect of ion-etching and film deposition on flexural strength was negligible for these conditions. However, after etching and coating, a small increase of the fracture resistance was observed for the GTT treated WC-Co (the condition that most closely mimics the situation of a cutting tool in operation) and interpreted as a beneficial effect of the deposited film on the surface residual stress state. As a final result, the differences in fracture resistance which is ascribed to changes of the grinding-induced surface integrity were effectively reduced during the ion etching and coating processes. 


\section{Acknowledgements}

Funding for this investigation was partly supplied by the Grant No. MAT 2015-70780-C4-3-P (MINECO/FEDER). One of the authors (J.Y.) acknowledges funding received through Erasmus Mundus joint European Doctoral Programme DocMASE.

\section{References}

[1] Prakash L. 1.02 - Fundamentals and General Applications of Hardmetals. In: Sarin VK, Mari D, Llanes L (Eds.) Comprehensive Hard Materials. Oxford: Elsevier; 2014. Vol. 1, p. 29-90.

[2] Exner HE. Physical and chemical nature of cemented carbides. Int Met Rev. 1979;24:149-73.

[3] Roebuck B, Almond EA. Deformation and fracture processes and the physical metallurgy of WC-Co hardmetals. Int Mat Rev. 1988;33:90-112.

[4] Gurland J. New scientific approaches to development of tool materials. Int Mat Rev. 1988;33:151-66.

[5] Llanes L, Anglada M, Torres Y. 1.11 - Fatigue of Cemented Carbides. In: Sarin VK, Mari D, Llanes L (Eds.) Comprehensive Hard Materials. Oxford: Elsevier; 2014. Vol. 1, p. 345-62.

[6] Shatov AV, Ponomarev SS, Firstov SA. 1.10 - Fracture and Strength of Hardmetals at Room Temperature. In: Sarin VK, Mari D, Llanes L (Eds.) Comprehensive Hard Materials. Oxford: Elsevier; 2014. Vol. 1, p. 301-43.

[7] Fischmeister H. Development and present status of the science and technology of hard materials. In: Viswanadham RK, Rowcliffe DJ, Gurland J (Eds.) Science of Hard Materials: Springer US; 1983, p. 1-45.

[8] Fang ZZ. Correlation of transverse rupture strength of WC-Co with hardness. Int J Refract Met Hard Mater. 2005;23:119-27.

[9] Cha SI, Lee KH, Ryu HJ, Hong SH. Effect of size and location of spherical pores on transverse rupture strength of WC-Co cemented carbides. Mater Sci Eng A. 2008;486:404-8.

[10] Byrne G, Dornfeld D, Denkena B. Advancing cutting technology. CIRP Ann-Manuf Techn. 2003;52:483-507. 
[11] Bouzakis KD, Michailidis N, Skordaris G, Bouzakis E, Biermann D, M'Saoubi R. Cutting with coated tools: coating technologies, characterization methods and performance optimization. CIRP Ann-Manuf Techn. 2012;61:703-23.

[12] Fang ZZ, Koopman MC, Wang H. 1.04 - Cemented Tungsten Carbide Hardmetal-An Introduction. In: Sarin VK, Mari D, Llanes L (Eds.) Comprehensive Hard Materials. Oxford: Elsevier; 2014. Vol. 1, p. 123-37.

[13] Hegeman JBJW, De Hosson JTM, de With G. Grinding of WC-Co hardmetals. Wear. 2001;248:187-96.

[14] M'Saoubi R, Outeiro JC, Chandrasekaran H, Dillon Jr OW, Jawahir IS. A review of surface integrity in machining and its impact on functional performance and life of machined products. Int J Sustain Manuf. 2008;1:203-36.

[15] Jawahir IS, Brinksmeier E, M'Saoubi R, Aspinwall DK, Outeiro JC, Meyer D, Umbrello D, Jayal AD. Surface integrity in material removal processes: Recent advances. CIRP AnnManuf Techn. 2011;60:603-26.

[16] Odén M, Almer J, Håkansson G. The effects of bias voltage and annealing on the microstructure and residual stress of arc-evaporated $\mathrm{Cr}-\mathrm{N}$ coatings. Surf Coat Tech. 1999;120-121:272-6.

[17] Odén M, Almer J, Håkansson G, Olsson M. Microstructure-property relationships in arcevaporated Cr-N coatings. Thin Solid Films. 2000;377-378:407-12.

[18] Knotek O, Löffler F, Krämer G. Substrate- and interface-related influences on the performance of arc-physical-vapour-deposition-coated cemented carbides in interrupted-cut machining. Surf Coat Tech. 1992;54-55, Part 2:476-81.

[19] Denkena B, Breidenstein B. Residual stress distribution in PVD-coated carbide cutting tools: Origin of cohesive damage. Tribol Ind. 2012;34:158-65.

[20] Breidenstein B, Denkena B. Significance of residual stress in PVD-coated carbide cutting tools. CIRP Ann-Manuf Techn. 2013;62:67-70.

[21] Mitterer C. 2.16 - PVD and CVD Hard Coatings. In: Sarin VK, Mari D, Llanes L (Eds.) Comprehensive Hard Materials. Oxford: Elsevier; 2014. Vol. 2, p. 449-67.

[22] Llanes L, Casas B, Idanez E, Marsal M, Anglada M. Surface integrity effects on the fracture resistance of electrical-discharge-machined WC-Co cemented carbides. J Am Ceram Soc. 2004;87:1687-93. 
[23] Jiang D, Anne G, Vleugels J, Vanmeensel K, Eeraerts W, Liu W, Lauwers B, Van der Biest O. Residual stresses in hardmetals caused by grinding and EDM machining and their influence on the flexural strength. 16th International Plansee Conference. Reutte, Austria 2005. p. 1075-85.

[24] Lauwers B, Liu W, Eeraerts W. Influence of the composition of WC-based cermets on manufacturability by wire-EDM. J Manuf Process. 2006;8:83-9.

[25] Sakagami K, Yamamoto T. Study on bending and compressive fatigue characteristics of cemented carbides. J Jpn Soc Powder Powder Metall. 2006;53:202-7.

[26] Casas B, Torres Y, Llanes L. Fracture and fatigue behavior of electrical-discharge machined cemented carbides. Int J Refract Met Hard Mater. 2006;24:162-7.

[27] Yang J, Odén M, Johansson-Jõesaar MP, Llanes L. Grinding effects on surface integrity and mechanical strength of WC-Co cemented carbides. Procedia CIRP. 2014;13:257-63.

[28] Tönshoff HK, Seegers H. Influence of residual stress gradients on the adhesion strength of sputtered hard coatings. Thin Solid Films. 2000;377-378:340-5.

[29] Yang J, Roa JJ, Odén M, Johansson-Jõesaar MP, Esteve J, Llanes L. Substrate surface finish effects on scratch resistance and failure mechanisms of TiN-coated hardmetals. Surf Coat Tech. 2015;265:174-84.

[30] Yang J, García Marro F, Trifonov T, Odén M, Johansson-Jõesaar MP, Llanes L. Contact damage resistance of TiN-coated hardmetals: Beneficial effects associated with substrate grinding. Surf Coat Tech. 2015;275:133-41.

[31] Yang J, Odén M, Johansson-Jõesaar MP, Llanes L. Influence of substrate microstructure and surface finish on cracking and delamination response of TiN-coated cemented carbides. Wear. 2016;352-353:102-11.

[32] Casas B, Lousa A, Calderón J, Anglada M, Esteve J, Llanes L. Mechanical strength improvement of electrical discharge machined cemented carbides through PVD (TiN, TiAlN) coatings. Thin Solid Films. 2004;447-448:258-63.

[33] Llanes L, Casas B, Torres Y, Salán N, Mestra A. Fatigue performance improvement of electrical discharge machined hardmetals by means of combined thermal annealing and surface modification routes. Int J Refract Met Hard Mater. 2013;36:60-5. 
[34] Sheikh S, M'Saoubi R, Flasar P, Schwind M, Persson T, Yang J, Llanes L. Fracture toughness of cemented carbides: Testing method and microstructural effects. Int J Refract Met Hard Mater. 2015;49:153-60.

[35] Exner HE. The influence of sample preparation on the surface stress state and Palmqvist's method for toughness testing of cemented carbides. Trans Metall Soc AIME. 1969;245:677.

[36] Torres Y, Casellas D, Anglada M, Llanes L. Fracture toughness evaluation of hardmetals: influence of testing procedure. Int J Refract Met Hard Mater. 2001;19:27-34.

[37] Eigenmann B, Macherauch E., Röntgenographische untersuchung von spannungszuständen in werkstoffen. Mater Werkst. 1996;27:426-37.

[38] Merklein M, Andreas K, Engel U. Influence of machining process on residual stresses in the surface of cemented carbides. Procedia Eng. 2011;19:252-7.

[39] Mari D, Krawitz AD, Richardson JW, Benoit W. Residual stress in WC-Co measured by neutron diffraction. Mater Sci Eng A. 1996;209:197-205.

[40] Larsson C, Odén M. X-ray diffraction determination of residual stresses in functionally graded WC-Co composites. Int J Refract Met Hard Mater. 2004;22:177-84.

[41] Livescu V, Clausen B, Paggett JW, Krawitz AD, Drake EF, Bourke MAM. Measurement and modeling of room temperature co-deformation in WC-10 wt.\% Co. Mater Sci Eng A. 2005;399:134-40.

[42] Krawitz AD, Drake EF. 1.13 - Residual Stresses. In: Sarin VK, Mari D, Llanes L (Eds.) Comprehensive Hard Materials. Oxford: Elsevier; 2014. Vol. 1, p. 385-404. 


\section{$\sigma(\mathrm{MPa})$}

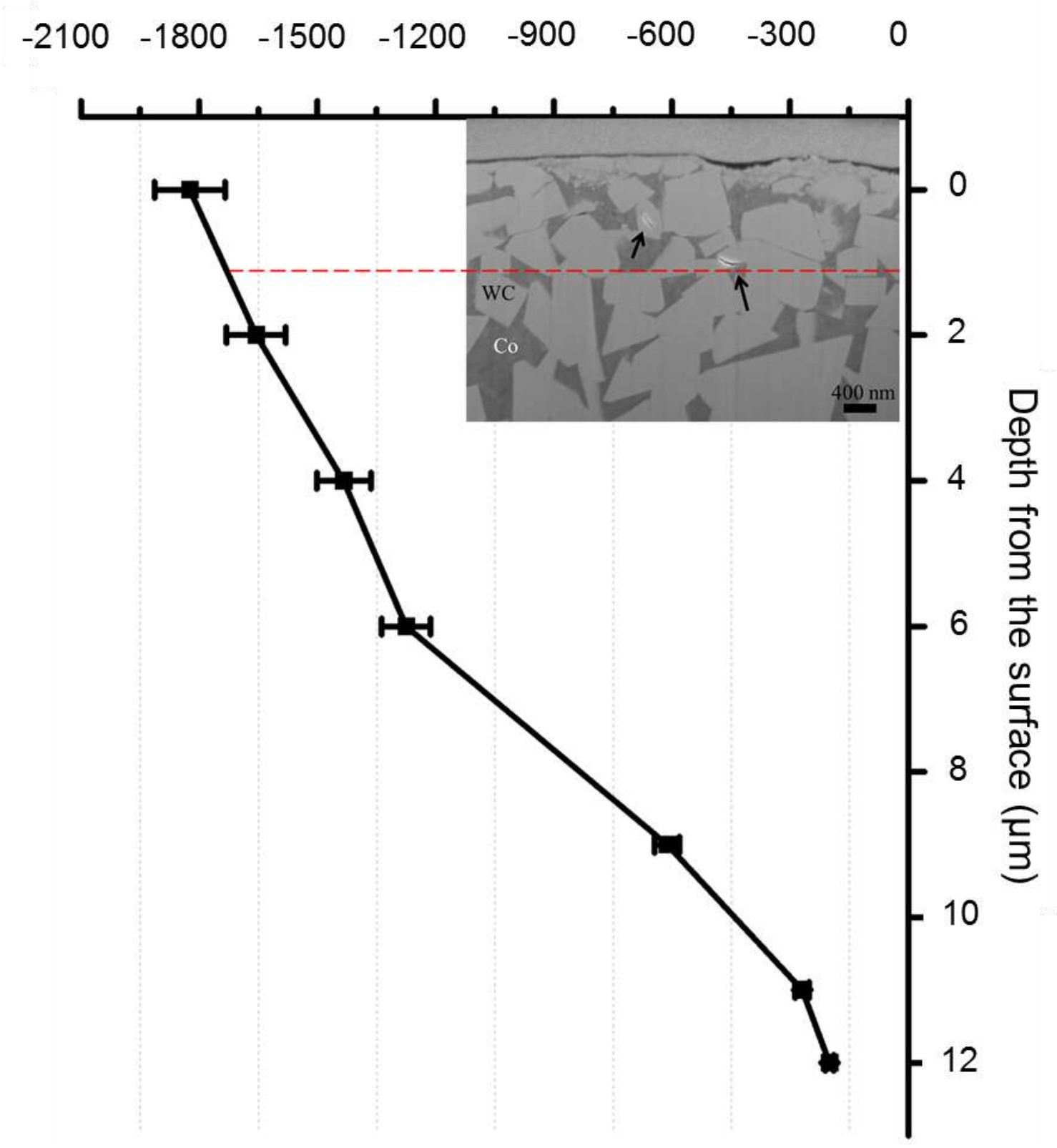

Fig. 1 Schematic graph showing thickness of subsurface layers where grinding-induced damage and residual stresses are evidenced. Dashed line indicates the deepest location where microcracks are observed. Note that grinding-induced residual stresses extend well beyond the thickness estimated for such deformed/damaged layer. 


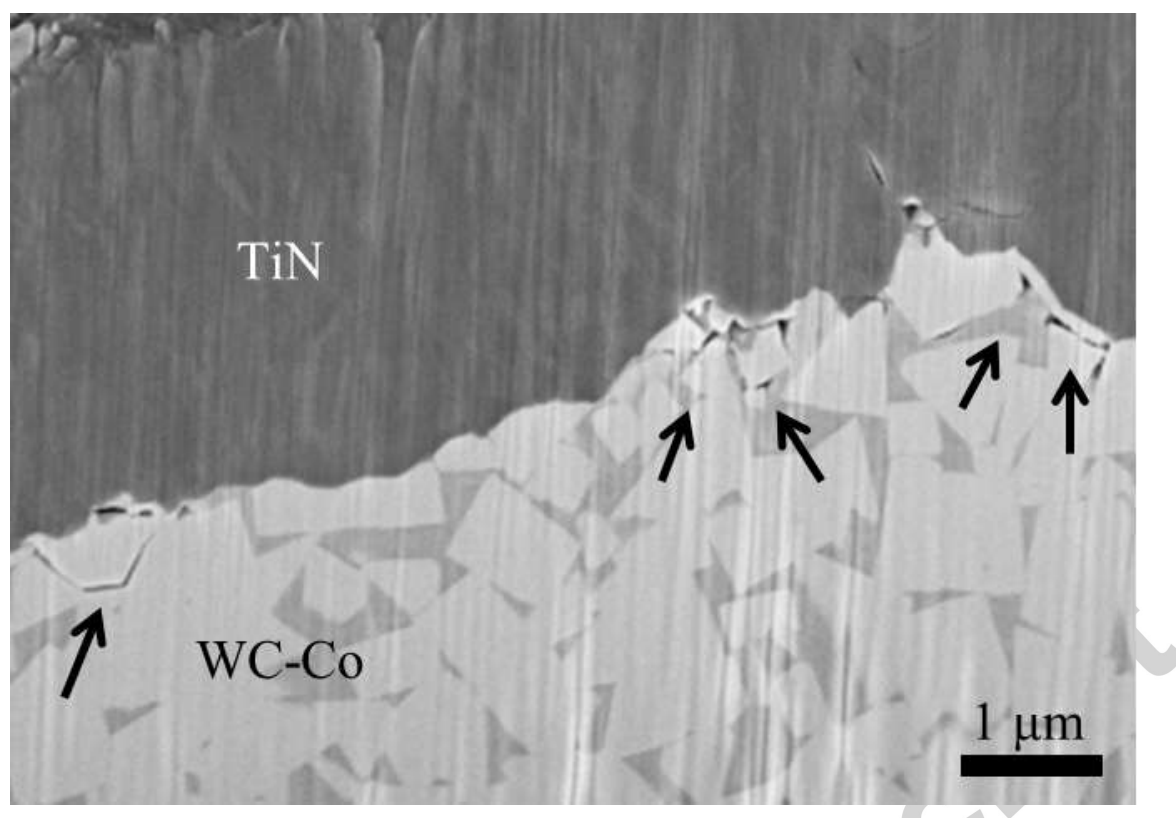

Fig. 2 Cross-section view of a ground, ion-etched and finally coated hardmetal. Note that FIB milling was made perpendicular to the grinding marks, and grinding-induced damage is pointed out with arrows. 


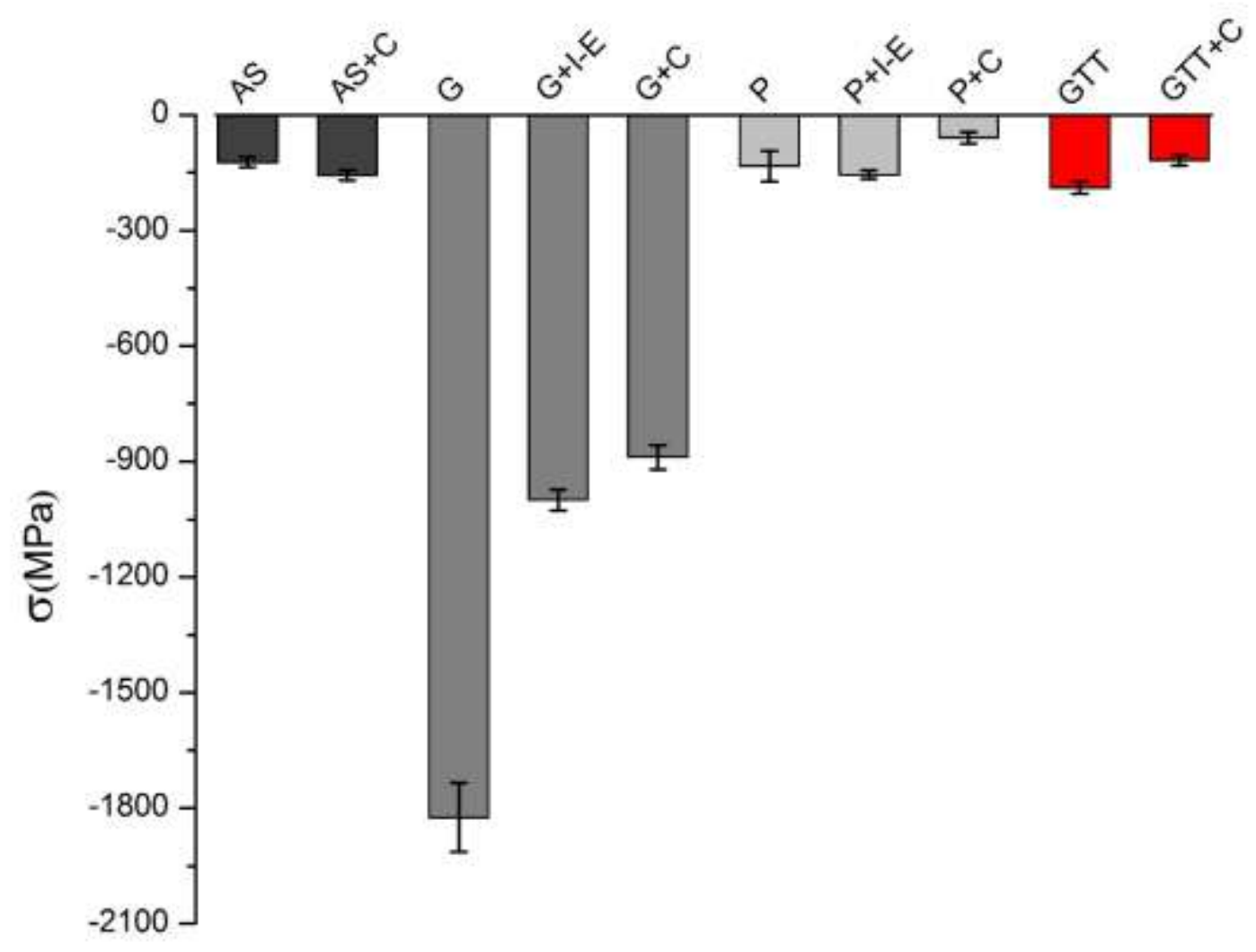

Fig. 3 Residual stresses measured in the WC phase at the hardmetal surface (uncoated and ionetched [I-E] conditions) or at the interface level (coated [C] variants) associated with different hardmetal surface finish conditions: AS, G, P and GTT. 


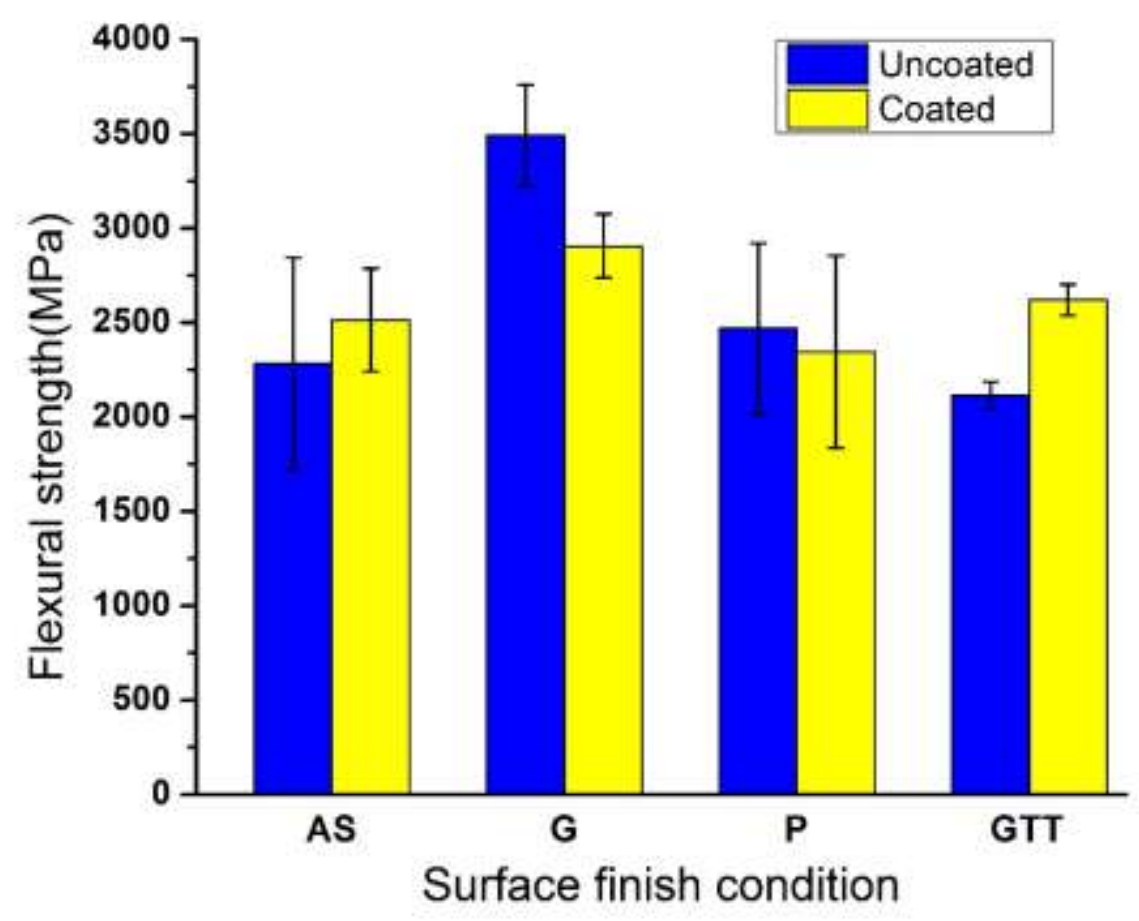

Fig. 4 Flexural strength of uncoated (blue columns) and coated (yellow columns) WC-Co specimens, corresponding to the different surface conditions studied. 

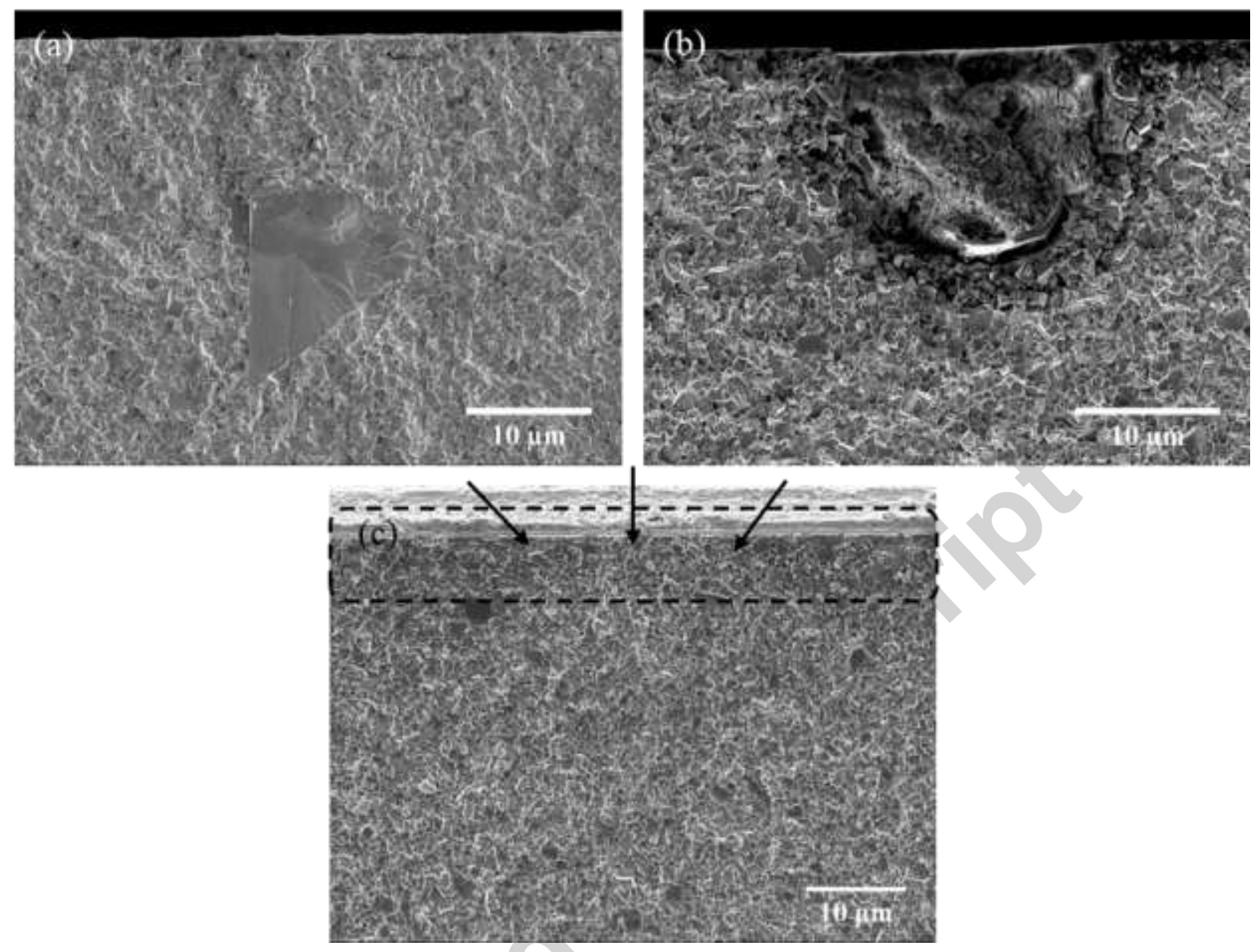

Fig. 5 FESEM micrographs of representative failure initiation sites for uncoated specimens: (a) internal large carbide grain for $\mathrm{G}$ sample, (b) surface pore for $\mathrm{P}$ sample, and (c) grinding-induced surface damage for GTT sample (indicated by arrows). 

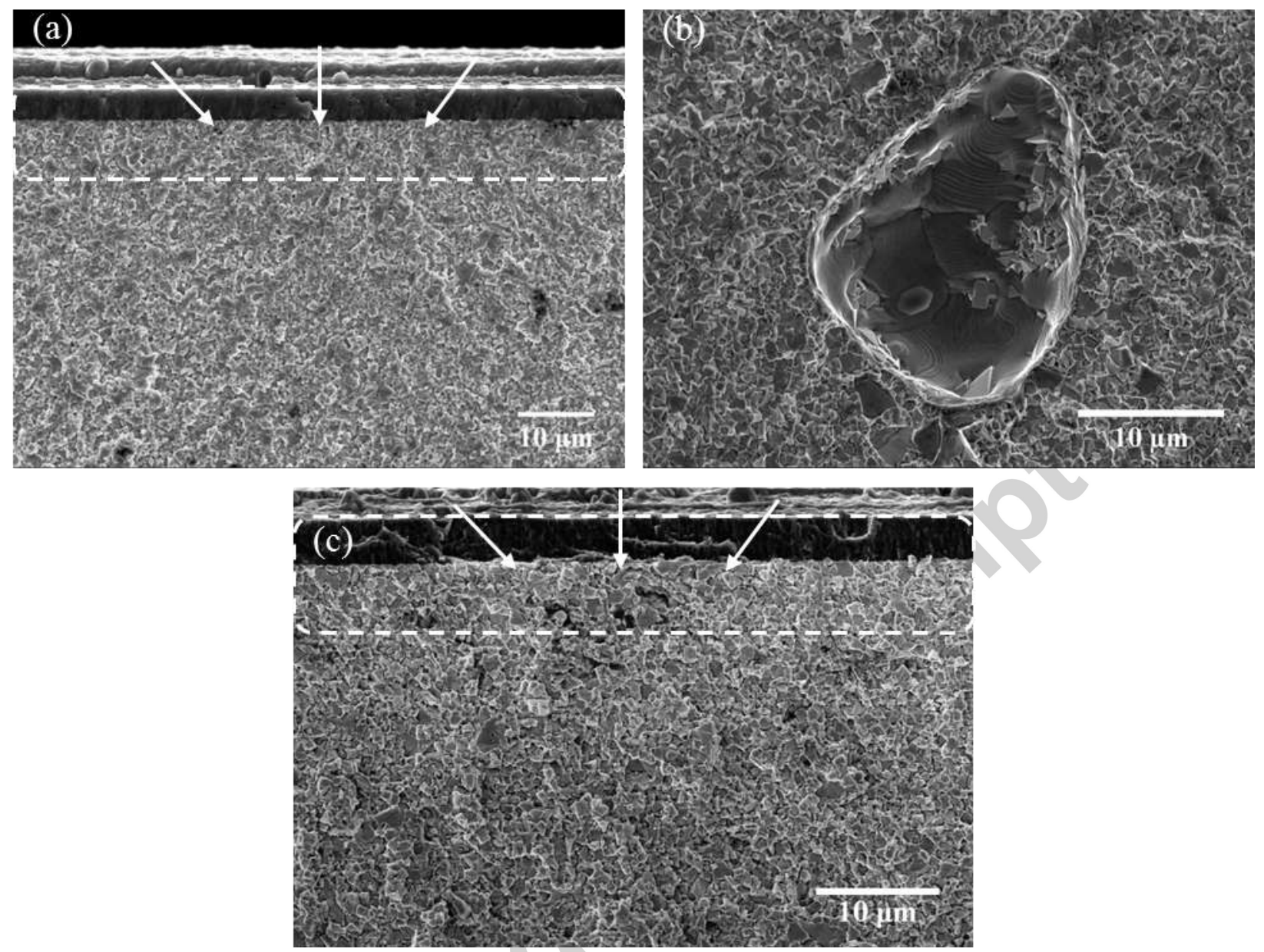

Fig. 6 FESEM micrographs of representative failure initiation sites for coated samples: (a) damage-like flaws located at the surface hardmetal substrate for coated G sample (indicated by arrows); (b) intrinsic pore near the surface for coated AS sample; and (c) grinding-induced surface damage for coated GTT sample (indicated by arrows). 